\title{
Moving Beyond Citation Analysis: How Surveys and Interviews Enhance, Enrich, and Expand Your Research Findings
}

\author{
Susann deVries, Robert Kelly, and Paula M. Storm
}

\begin{abstract}
A traditional mixed methods research model of citation analysis, a survey, and interviews was selected to determine if the Bruce T. Halle Library at Eastern Michigan University owned the content that faculty cited in their research, if the collection was being utilized, and what library services the faculty used. The combination of objective data gleaned from the citation analysis and survey coupled with the personal, in-depth information gained from the interviews was instrumental in increasing the value of the study for its use in collection management decisions, and showed how effectual the services and collection are in supporting the research needs of the faculty at EMU.
\end{abstract}

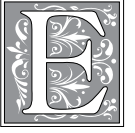

astern Michigan University (EMU) is a public university located in Ypsilanti, Michigan, about 7 miles from the University of Michigan in Ann Arbor. Founded in 1849 as Michigan State Normal School, it specialized in the training of teachers. Today, EMU continues its legacy as an institution that stresses education and serves nearly 700 faculty and 20,000 students. Though offering masters' and doctoral degrees in a number of subject areas, EMU focuses primarily on the achievement of its undergraduate students.

While the mission of the EMU Halle Library is primarily to support the needs of the undergraduate students, we wanted to know if the library collection was meeting the research needs of our faculty. We wanted to verify the following: if the library owned the content faculty used for research; if the collection was being used; and what services the faculty used. After conducting the study, the library planned to evaluate the collection and use the findings to help identify potential collection development needs.

Citation analysis and the impact factor of journals are time-honored ways to determine how well a library is meeting the research needs of faculty. They contribute valuable data that help librarians determine the journals, books, and other resources to purchase, which is particularly important in this age of difficult economic times and decreases in funding. However, the measure of a library is more

Susann deVries is Instructor, Robert Kelly is Assistant Professor and Pamela M. Storm is Assistant Professor in the Bruce T. Halle Library at Eastern Michigan University; e-mail: sdevries@emich.edu, Robert.kelly@ emich.edu, and pstorm@emich.edu. (c) Susann deVries, Robert Kelly, and Pamela M. Storm 
than its collection, and citation analysis alone can be a narrow, biased measure that does not include the more subjective, qualitative, personal information that can be extremely useful in measuring the effectiveness of the collection and services of an academic library.

Adding a survey and personal interviews to citation analysis helped the EMU Halle Library gain an in-depth understanding of how and where our faculty publish, how our collections meet their research needs, how they personally use the library, and what can be done to improve its resources and services.

During this study, the publication type to which we refer will default to "article." This does not mean that books, government documents, reports, or other types of publication are not included.

\section{Review of the Related Literature}

The use of citation analysis has been used for many years to help evaluate the collection and services of a library. In 1927, Gross and Gross used an early method of citation analysis to determine the purchase of journal subscriptions in a chemistry library. ${ }^{1}$ This process of counting citations was significantly improved in the late 1960s when Eugene Garfield founded ISI and developed modern citation analysis. Garfield, along with Irving Sher, also discovered the "impact factor" of journals, as published in Journal Citation Reports (JCR), which determines the relative importance of a journal title by its citations. ${ }^{2}$ This journal impact factor was deemed necessary to determine core journals in a discipline without neglecting the smaller, influential review journals. ${ }^{3}$

Studies and applications describing the use of citation analysis for collection management include Sherri Edwards' analysis of the citations in the field of polymer science at the University of Akron. ${ }^{4}$ Wilson and Tenopir used citation analysis to study how well the research collection supported faculty at the University of South Wales. ${ }^{5}$ Erin T. Smith analyzed citations from theses and dissertations to determine if the University of Georgia Libraries supported their graduate students' research needs. ${ }^{6}$

ISI continues to be the premier resource for citation analysis. The strengths of ISI Web of Knowledge (C) (ISI) include the 10,000 high-impact journals indexed, and the powerful capacity for citation searching. Pancheshnikov used ISI in the comparative analysis of faculty publication citations with those of student theses at the University of Saskatchewan. ${ }^{7}$ Enssle and Wilde named citation analysis using ISI as one way to determine journal cancellations. ${ }^{8}$ Ralston, Gall, and Brahmi at the Indiana University School of Medicine Library also used ISI and JCR to investigate their journal selection process. ${ }^{9}$ Another study by Bensman demonstrated how using ISI and JCR can be used to compare citations in various disciplines. ${ }^{10}$

Though used mainly for journal assessment, citation analysis can also be used to develop a book collection. For example, Enger selected books by highly cited authors and compared the circulation statistics of these books against those selected by more traditional methods. ${ }^{11}$

However, using ISI for our citation analysis limited our study, because the journals identified are only those included in the ISI database, and articles are increasingly published online via openaccess journals, personal homepages, or institutional repositories and therefore are not indexed in ISI. ISI has also been criticized for being biased toward English language journals, not reflecting local usage, and not always including all of the personal names in multiauthored articles. $^{12}$

To expand beyond citation analysis, we incorporated a mixed-methods research approach. Mixed-methods research has been evolving as a pragmatic approach in research design to consider multiple perspectives, viewpoints, and standpoints of both qualitative and quantitative research. Prevalent in the social and behavioral sciences throughout most of the twentieth century, mixed-methods research, or 
sometimes referred to as multimethod research, is becoming "recognized as the third major research approach or research paradigm, along with qualitative research and quantitative research." ${ }^{13}$ Recent books published by authors Ridenour and Newman, ${ }^{14}$ Creswell and Plano Clark, ${ }^{15}$ and Tashakkori and Teddlie ${ }^{16}$ bring to light the recent thoughts and importance of using both quantitative and qualitative research methods to provide the most revealing, inclusive, and constructive research results.

While mixed-methods research continues to struggle with language, techniques, research designs, methodologies, and its application to specific disciplines, ${ }^{17}$ this study used mixed-methods research in the traditional sense of incorporating both quantitative and qualitative research. By incorporating a survey and interviews, we enhanced our understanding of the data collected from our citation analysis.

\section{Methodology}

Therefore, to begin our research we used ISI, including Science Citation Index, Social Science Citation Index, and Arts \& Humanities Citation Index, to retrieve all records for the years 2005-2007 citing Eastern Michigan University as the organization name. We further refined this list by limiting to articles only. This gave us a list of 244 citations to articles authored by EMU-affiliated faculty. This list was then downloaded and saved as a CSV (comma-separated value) file and was used to determine the most frequently published EMU authors, the departments with which they are affiliated, and the journals in which they publish.

The second step was to extract the article citations the authors used to write their articles. There were 8,639 citations found, downloaded, and saved as a CSV file. The authors' list and cited reference list were formatted into a single file and parsed using Perl scripts creating tables with columns listing the authors, published articles, and citations. The resulting tables were then imported into an Ac- cess@ database by our systems librarian, Jackie Wrosch.

This list contained the following fields: title; ISSN; publication year; format; volume; and a column for notes. An additional column was added where ownership could be indicated. The list was used to determine whether or not we owned the titles cited in the author's bibliographies.

The list was very long, so we divided it into three sections and each of us began the arduous process of interpreting the citations and establishing ownership. Ownership was defined as owning the resources in print or providing electronic access. Web sites that are freely available were considered "owned."

\section{Survey}

From the citation analysis, we knew we would be able to present explicit numbers indicating whether or not the library collection could support faculty research. However, we wanted to determine if, in fact, EMU faculty were actually using the resources of the EMU Halle Library for their research.

Working with statistician Professor Joe Scazzero, an anonymous online survey was designed using Survey Monkey@ and then distributed via e-mail to all of the identified EMU faculty authors to determine their use of the Eastern Michigan University Halle Library, the nearby University of Michigan libraries, and other academic libraries in southeast Michigan. In addition, the faculty authors were asked to identify the department with which they are affiliated and provide extended comments about the EMU Halle Library services and resources. We asked the following questions:

1. Did you use the EMU Halle Library's resources for the articles that you published between 2005 and 2007?

2. Which EMU Halle Library resources or services did you use for your research?

3. If the EMU Halle Library did not have the information you needed, what other resources did you use? 
4. Please indicate all other libraries you used for your research.

5. Why did you use these specific libraries' resources for your research?

6. What are the resources or services you used at these other libraries?

7. With what EMU department are you affiliated?

8. Please comment on how well EMU library resources supported your research for the articles you published between 2005 and 2007.

\section{Interviews}

As the third step in our methodology, we anticipated we would need to interview a subset of highly published authors to further probe their research-seeking strategies and their use of our collection. Due to survey fatigue and brevity of comments that often accompany online surveys, we wanted further clarification and discussion with faculty to verify survey findings and flesh out our understanding of their library usage and needs. To determine which authors to interview, the list of all EMU authors generated by our ISI citation analysis were sorted by college and then a representation of highly published faculty were selected for personal interviews. Each of us interviewed 2-3 faculty members in the colleges of Education and Arts \& Sciences. Departments of Biology, Chemistry, Teacher Education, Special Education, and Mathematics were represented.

The interviews were conducted to help us probe how the library can better support faculty with their research needs. Using a list of predetermined questions, we conducted the interviews within two weeks of the completion of the survey. We focused on the verbal narrative between ourselves and the faculty member. This interviewing method allowed for casual conversation, openness, candor, and spontaneous questions.

We began the interviews by asking the following predetermined questions:

1. How did you go about locating information for your publication research?
2. What, from the Halle Library collection, worked well for you?

3. Did you encounter any obstacles?

\section{Results and Discussion Citation Analysis}

Analysis of the citations revealed that, from 2005 through 2007, 121 Eastern Michigan University faculty authored 244 articles, which were published in 209 unique journal titles, of which 183 $(87.65 \%)$ are currently owned by EMU. The 244 articles had a total of 8,639 cited references of which 6,171 (71.43\%) were owned by the library (see figure 1).

Analyzing the 6,171 owned references by material type determined that 5,054 $(83 \%)$ were journals and $855(13 \%)$ were books. The remaining 262 items (4\%) were government documents, technical reports, Web sites, and other material types (see figure 2).

We were surprised by the level of ownership of both the journals and citations, given the university's focus on undergraduate education and not research. It was especially striking to us considering that, as part of our ongoing diligent journal review process, we cancelled a large number of journals over the past five years due to budget constraints.

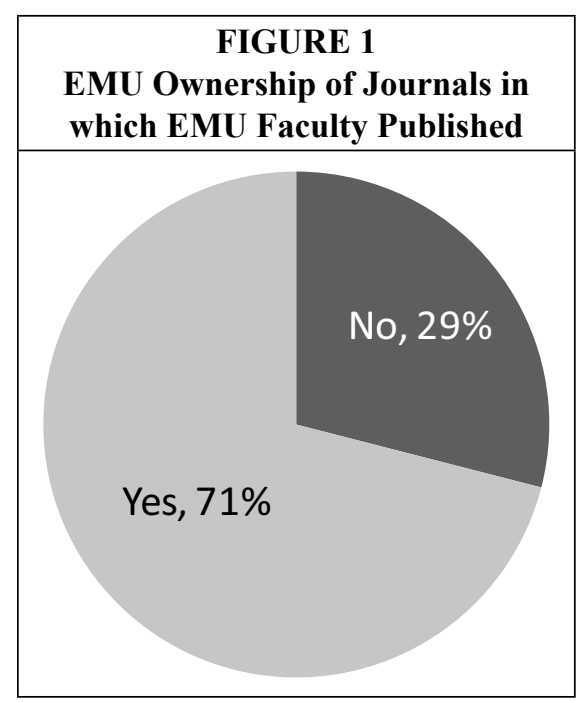




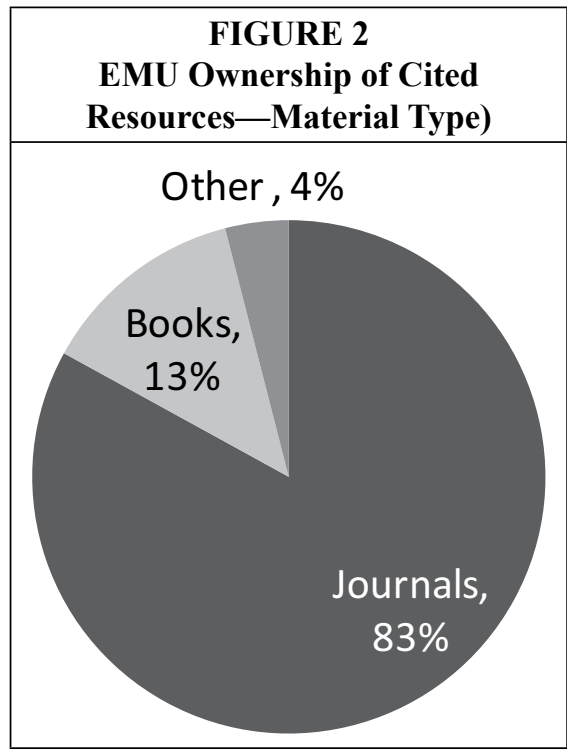

We used Web of Knowledge's Journal Citation Reports (JCR) to determine the quality of resources being cited by EMU faculty. Selecting 100 of the most frequently cited titles ( 50 owned and 50 not owned by the library) we obtained JRC data on 73 of the titles. Overall, the average "impact factor" was 4.160 and the average number of citations per title was 20.1096 .

Nature had the highest impact factor at 28.751, while Advertising Research came in at .395. Most frequently cited title was Ecology (66 citations), and the lowest was The American Journal of Community Psychology with 4 citations.

To obtain an impact/use (I/U) factor that reflects a title's impact factor and use by EMU faculty, we multiplied a journal's impact factor times the number of times it was cited by an EMU author. This calculation showed that Science, Nature, and $J A M A$ had the highest $\mathrm{I} / \mathrm{U}$ factors (870, 805, 613, respectively), while Urban Geographer, Journal of Criminal Justice, and Journal of Freshwater Ecology had the lowest (3.246, 2.34, and 2.26, respectively). The average I/U factor was 105.261. EMU owned all titles with I/U factors of 45.276 or higher (34 titles), again confirming that our collection appears to be meeting the research needs for our faculty.
From a collection development standpoint, the I/U factor is a helpful factor considering whether to subscribe to or cancel a journal title.

We also wanted to know what broad disciplines and departments were doing the most publishing at EMU. The most frequently cited journals were in the science subject areas $(68 \%)$. The results were almost certainly biased toward the sciences because of the heavy emphasis in ISI on journal literature as opposed to books where many of those in the social sciences and education publish. Even though we included the Arts \& Humanities Citation Index, the humanities were still not well represented by EMU faculty publications. In retrospect, we now realize the need to explore WorldCat and databases covering the humanities to locate where EMU humanities faculty publishes.

In the sciences, biology was the department with the most publications, with 35 percent. Of the total, chemistry added

\begin{tabular}{|c|}
\hline $\begin{array}{c}\text { TABLE } 1 \\
\text { EMU Most Frequently Cited } \\
\text { Journals }\end{array}$ \\
\hline Ecology $(66)$ \\
\hline $\begin{array}{l}\text { Journal of the American Chemical } \\
\text { Society (63) }\end{array}$ \\
\hline Journal of Chemical Physics (48) \\
\hline Journal of Biological Chemistry (44) \\
\hline $\begin{array}{l}\text { Journal of Personality and Social } \\
\text { Psychology (40) }\end{array}$ \\
\hline American Journal of Psychiatry (39) \\
\hline Physica A (38) \\
\hline Langmuir (35) \\
\hline Journal of Coating Technology (34) \\
\hline Journal of Personality Disorders (33) \\
\hline Science (33) \\
\hline Journal of Abnormal Psychology (31) \\
\hline Psychological Bulletin (31) \\
\hline Journal of Experimental Biology (29) \\
\hline Journal of Personality Assessment (29) \\
\hline Academic Management Journal (28) \\
\hline $\begin{array}{l}\text { Journal of Consulting and Clinical } \\
\text { Psychology (28) }\end{array}$ \\
\hline Nature (28) \\
\hline
\end{tabular}




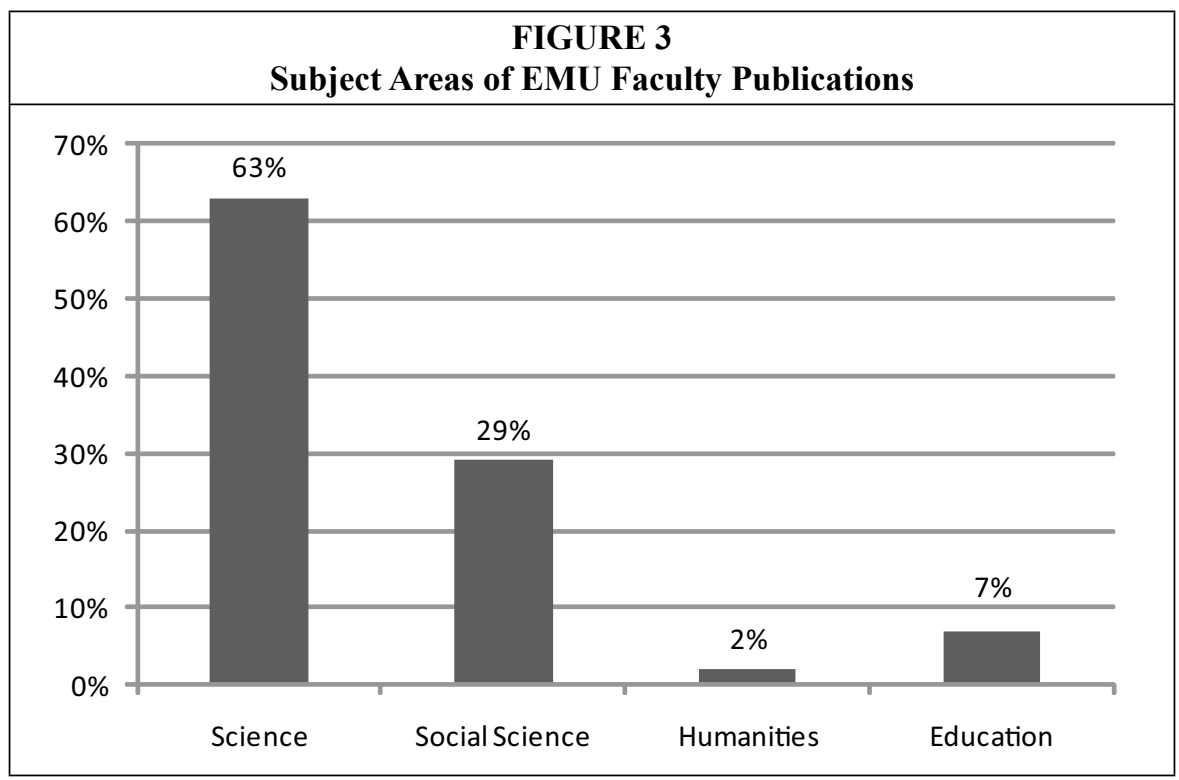

another 12 percent and mathematics added 10 percent.

\section{Journal Citation Reports}

Using the 2007 Journal Citation Reports (JCR) data, we completed a journal citation analysis of the 100 most frequently cited journals (50 owned and 50 not owned by the library). Our intent was to determine the "quality" of the journals being cited by identifying their impact factor. Knowing this would also enable us to determine if our collection was missing core journals being cited by EMU faculty.

In summary, we found 73 out of 100 titles in JCR. Of the 27 titles not in JCR, EMU owns four of them. The 27 titles cited 252 publications. Interestingly, 95 or 37.6 percent of these citations were found in the four titles owned by EMU. One title, Journal of Coatings Research, was included in our list of the 20 most frequently cited journals; this was not surprising given that EMU is home to the Coatings Research Institute. Of the titles on the JCR list that EMU does not own, the highest impact factor (IF) titles are Neurology (IF 6.014 with 7 citations), and Environmental Planning A (IF 1.726 with 20 citations).
Of the 73 cited journals found in JCR, 50 were owned by EMU and cited 1,351 times, equaling 86.43 percent of all the JCR title citations and 15.64 percent of all EMU citations. In addition, 19 of the 20 most frequently cited journals are on the JCR list. The above analysis indicates that the EMU faculty were citing quality publications in their research.

Ecology (IF: 4.822 with 66 citations) and Canadian Journal of Zoology (IF: 1.493 with 17 citations) are the highest/lowest cited titles in the list. Comparing the IF to the 20 most heavily cited journals, Nature and Science, with the highest impact factors of 28.71 and 26.372 , were ranked 17 th and 10th on the list.

\section{Survey}

After completing the citation analysis, using an anonymous, online survey, we wanted to determine whether or not the faculty authors used the EMU Halle Library for the articles they published that were included in the study. There were 124 participants surveyed, with a return rate of 28 percent. We were pleased with our response rate, as past surveys regarding Halle Library's resources in 2006 resulted in a faculty return rate of 
approximately 12 percent and a 2003 LibQUAL survey reported a faculty return rate slightly over 13 percent. The high return rate for this study's survey could be attributed to the tailored constituency of the study group, the personalized request from the researchers, and the added interest for faculty to aid our research.

Ninety-four percent of the respondents reported using the EMU Halle Library for their research. While 100 percent utilization response would be ideal, the specializations and esoteric research topics of published faculty make this number more than acceptable.

1. Did you use the EMU Halle Library's resources for the articles that you published between 2005 and 2007?

Yes 94\%

No 6\%

The second question was aimed at finding out exactly what resources and/ or services they used at the EMU Halle Library. Respondents were encouraged to indicate all of the library resources they used. Almost 80 percent of the respondents used the databases, which include the full-text journal databases. Three out of four surveyed used the journal collection. In the survey, we did not ask them to distinguish between online or print journals. Half of the respondents used Interlibrary Loan to fulfill their research needs and reported being very satisfied with this service.

2. Which EMU Halle Library resources or services did you use for your research?

Databases 79\%

Journals $77 \%$

Books 71\%

ILL 50\%

Archives 6\%

Maps 6\%

Reference Works 3\%

Subject Guides 3\%

Subject Librarian 3\%

Other 3\%

In the survey, we were also interested in learning what other resources were used to fulfill their research needs for the article they wrote in 2005-2007. As indicated below, most faculty used other libraries to find the information they needed.

3. If the EMU Halle Library did not have the information you needed, what other resources did you use?

Another library 68\%

Web sites $46 \%$

Personal library $46 \%$

Colleagues $\quad 32 \%$

Departmental library 11\%

Not surprisingly, most faculty surveyed used the libraries of the University of Michigan (U of M) to supplement their research needs. $U$ of $M$ is a major research university with 40,000 students and is located 7 miles away from Eastern Michigan University. EMU faculty have borrowing privileges there.

4. Please indicate all other libraries you used for your research.

$\begin{array}{lll}\text { U of } \mathrm{M} & & 62 \% \\ \text { Other } & 21 \% & \\ \text { None } & 17 \% & \end{array}$

The reasons the faculty used another library ranged from being an alumnus/ na of the university to the location being close to home.

5. Why did you use these specific libraries' resources for your research?

Other $61 \%$

Close to home $39 \%$

Alumnus/na 22\%

Family member $22 \%$

Emeritus 4\%

Access to specific journal titles was the primary reason the faculty authors used these other libraries, especially the U of $\mathrm{M}$.

6. What are the resources or services you used at these other libraries?

Journals $79 \%$

Books $42 \%$

Databases 25\%

Other $13 \%$

Maps 8\%

Subject librarian $4 \%$

The final question of the survey asked with what department the faculty author was affiliated. Again, the STEM sciences 
were the most represented, followed by psychology and education.

7. With what EMU department are you affiliated?

STEM: Biology, Chemistry, Geology, Mathematics, Computer Science, Nursing, Physics, and Astronomy 51.61\%

History and Philosophy 3.23\%

Political Science $12.9 \%$

Psychology $12.9 \%$

Education $9.68 \%$

Business $6.45 \%$

Despite having a flat budget for five years running the collection and services, the EMU Halle Library appears to fulfill most of the faculty authors' research needs. The comment section of the survey gleaned important information that can be used for the improvement of the services and collection at the EMU Halle Library. While we may not own immediate access to all materials that faculty use for their research, the library needs to diligently educate and promote our interlibrary loan services to faculty.

8. Please comment on how well EMU library resources supported your research for the articles you published between 2005 and 2007.

The 29 comments reported for question number 8 were sorted and ranked on a 5-point Likert scale ranging from 1) the library not meeting their research needs to 5) the library completely meeting their research needs. None of the survey respondents indicated the library did not meet any of their research needs. The following are examples of a reply for each ranking:

1: $0 \%$ of respondents

2: $17 \%$ of respondents

"Not too well ... sorry! But, many of the journals I need cannot be accessed thru the EMU library."

3: $14 \%$ of respondents

"The resources were adequate, but could be better. If I could not access it at EMU, I went to U of M. I feel I should be able to access everything I need via EMU."

4: $21 \%$ of respondents
"Pretty well. There are occasional journal articles that are not accessible through our library, but I usually get them through ILL pretty quickly."

5: $48 \%$ of respondents

"I am pleased by EMU library resources. I wrote about a dozen papers in the last two years using references from EMU Library."

Therefore, as the numbers indicate, 69 percent of the faculty who responded to this question are satisfied with the collection holdings of EMU Halle Library and the support they receive for their research. The approval rate is encouraging due to the fact, in 2006, 56 percent reported the library's journal collection met their research needs to a great or moderate extent, while 46 percent felt similarly about the book collection. The vigorous ongoing liaison and collection development efforts are demonstrating positive results and hearten our continuous efforts.

\section{Interviews}

We completed our research with faceto-face interviews with faculty from the departments of Biology, Chemistry, Mathematics, Teacher Education, and Special Education to gain an in-depth understanding of how they personally used the library and what could be done to improve its resources. Faculty from the departments of Biology, Chemistry, and Mathematics were selected based on the number of articles published. Faculty from Teacher Education and Special Education were selected because of EMU's large College of Education.

Here at EMU, we have an active library liaison program between the library subject specialists and their designated departments on campus. The library faculty actively reaches out to faculty across campus to help develop student assignments, accept input for collection development decisions, and assist with information literacy needs. Because of the active liaison program, the highly published faculty we interviewed knew us well and readily accepted being interviewed. 
The predetermined questions used in the interviews were:

1. How did you go about locating information for your publication research?

2. What, from the Halle Library collection, worked well for you?

3. Did you encounter any obstacles?

Due to their comfort level, those interviewed were relaxed and willing to honestly discuss their perceptions of the library. The open dialogue allowed the interviews to move in new and unexpected directions, adding depth and breadth to our understanding of library usage. Fuller and richer understanding of participants' perspectives on a personal level enabled us to enhance the raw data collected from the survey and gain significant insights from one-on-one interviews.

The faculty interviewed stated that databases were the primary access point for locating information used in their research. One faculty member stated he used a database not affiliated with EMU; we do not subscribe to it as it is fairly esoteric. The fact that faculty members find databases useful in locating information for their research is not surprising due to our constant review of the relevance and usage of our databases. In addition, because of our liaison program we are in continuous dialog with departments and are well aware of their database requirements.

Interlibrary loan services were very much appreciated, and the enhanced ILL services, such as electronic delivery of journal articles, greatly assisted their research. While our ILLiad system provides real-time tracking, we were surprised to learn they still perceived the ILL service as being slow.

With the increase and availability of electronic journals, it is no wonder that faculty value the immediacy of research at their fingertips. This correlates with their request for the library to obtain electronic access to journals whenever possible. Several faculty indicated they do most of their research during breaks or while they are at their cabin at a distant location and do not have the required physical access to print journals.

One unexpected result gleaned from the interviews was due to the faculty confidence with the library's resources; they encourage their students to use Halle Library materials and are confident they will receive the in-depth help they need from librarians. Additionally, EMU faculty are sympathetic to our budget challenges and do not expect the library to subscribe to highly specialized publications that might directly support their research but would not likely be used by EMU students.

We concurred that the personal interviews, aided with the survey data and citation analysis, revealed new information that neither the survey nor the numeric analysis alone would yield, especially explanations of how faculty research affects students' library usage.

\section{Conclusions, Implications, and Recommendations}

The exploration/investigation for this study determined that the Bruce T. Halle Library at Eastern Michigan University is effectual in the services and collection it provides to support the research needs of its faculty at EMU. Continuous improvement process with the library liaison outreach and annual journal review has increased our faculty satisfaction rates.

The citation analysis revealed that EMU owns roughly 71 percent of all articles cited in the articles written by EMU faculty published between 2005 and 2007. This is considered a respectable percentage of ownership given the materials budget and the university's emphasis on faculty's involvement in the classroom. Most frequently cited journals and impact factor data indicates that the EMU faculty was using key publications in their research. It came as no surprise that 86 percent of all citations were referenced from journals. As monographs were only 11 percent of all the citations, the implication to collection development and allocation of funds for journals vs. 
monographs will be taken into consideration. When reviewing journal titles for cancellation, in addition to usage, citation analysis would be another measure for determining whether to retain or cancel a title.

Through the online survey distributed through Survey Monkey®, we were able to verify that EMU faculty accessed their resources through the EMU library and made use of the newly enhanced interlibrary loan service. It came as no surprise that faculty also make use of the collections in nearby institutions; such as the $U$ of $M$ located a mere seven miles west of EMU. As topics for research can be extremely specialized and involved, many reported using resources from their personal library that they have collected over the years. Not surprisingly, faculty primarily reported being affiliated with the STEM (science, technology, engineering, and mathematics) disciplines, followed by the departments of psychology and education. Faculty in the arts and humanities were not well represented. This is probably due to ISI's emphasis on journal literature. The final comment section of the survey indicated that the majority of the faculty is satisfied with the collection of the library and the services to meet their research needs.
We concurred that the personal interviews, aided with the survey data and citation analysis revealed new information that neither the survey nor the numeric analysis alone would yield. For example, virtually all faculty indicated that they seldom use print journals and that purchasing e-journals is clearly the best option for ensuring usage of journal content. Another key finding discovered during the interviews showed that faculty who are familiar with the Halle Library's holdings and use its resources encourage their students to use library materials and are confident they will receive the resources and in-depth assistance from librarians to meet their information needs. Their confidence in both the library collection and the subject librarians imparts greater information literacy skills to their students.

By using the three different research methods, we were able to enhance, enrich, and expand our research findings to complete a well-rounded picture of the library's collection, faculty research needs, and indirect implications to students' use of the library. As an outcome of conducting this research project, we hope to use the information gathered to build both our collection and communication with EMU faculty.

\section{Notes}

1. P.L.K. Gross and E.M. Gross, "College Libraries and Chemical Education,” Science 66, no. 1713 (1927): 385-89.

2. Eugene Garfield, "Citation Analysis as a Tool in Journal Evaluation: Journals can be Ranked by Frequency and Impact of Citations for Science Policy Studies," Science 178, no. 4060 (1972): 471-79.

3. Eugene Garfield, “Journal Impact Factor: A Brief Review," Canadian Medical Association Journal: CMAJ 161, no. 8 (1999): 979-80.

4. Sherri Edwards, "Citation Analysis as a Collection Development Tool: A Bibliometric Study of Polymer Science Theses and Dissertations," Serials Review 25, no. 1 (1999): 11-20.

5. Conception S. Wilson and Carol Tenopir, "Local Citation Analysis, Publishing and Reading Patterns: Using Multiple Methods to Evaluate Faculty use of an Academic Library's Research Collection," Journal of the American Society for Information Science and Technology 59, no. 9 (2008): 1393-1408.

6. Erin T. Smith, "Assessing Collection Usefulness: An Investigation of Library Ownership of the Resources Graduate Students Use," College E Research Libraries 64, no. 5 (2003): 344-55.

7. Yelena Pancheshnikov, "A Comparison of Literature Citations in Faculty Publications and Student Theses as Indicators of Collection Use and a Background for Collection Management at a University Library," Journal of Academic Librarianship 33, no. 6 (2007): 674-83.

8. Halcyon R. Enssle and Michelle L. Wilde, "So You Have to Cancel Journals? Statistics That 
Help," Library Collections, Acquisitions, E Technical Services 26 (2002): 259-81.

9. Rick Ralston, Carole Gall, and Frances A. Brahmi, “Do Local Citation Patterns Support Use of the Impact Factor for Collection Development?" Journal of the Medical Library Association 96, no. 4 (2008): 374-78.

10. Stephen J. Bensman, "Distributional Differences of the Impact Factor in the Sciences versus the Social Sciences: An Analysis of the Probabilistic Structure of the 2005 Journal Citation Reports," Journal of the American Society for Information Science and Technology 59, no. 9 (2008): 1366-82.

11. K. Brock Enger, "Using Citation Analysis to Develop Core Book Collections in Academic Libraries," Library E Information Science Research 31 (2009): 107-12.

12. Edwards, Serials Review: 11-20.

13. R.B. Johnson, A.J. Onwuegbuzie, and L.A. Turner, "Toward a Definition of Mixed Methods Research," Journal of Mixed Methods Research 1, no. 2 (2007): 112-33.

14. C.S. Ridenour and I. Newman, Mixed Methods Research: Exploring the Interactive Continuum (Carbondale: Southern Illinois University Press, 2008).

15. John W. Creswell and Vicki L. Plano Clark, Designing and Conducting Mixed Methods Research (Thousand Oaks, Calif.: Sage Publications, 2007).

16. Abbas Tashakkori and Charles Teddlie, eds., Handbook of Mixed Methods in Social E Behavioral Research (Thousand Oaks, Calif.: Sage Publications, 2003).

17. John W. Creswell, "Editorial: Mapping the field of Mixed Methods Research," Journal of Mixed Methods Research 3, no. 2 (2009): 95-108.

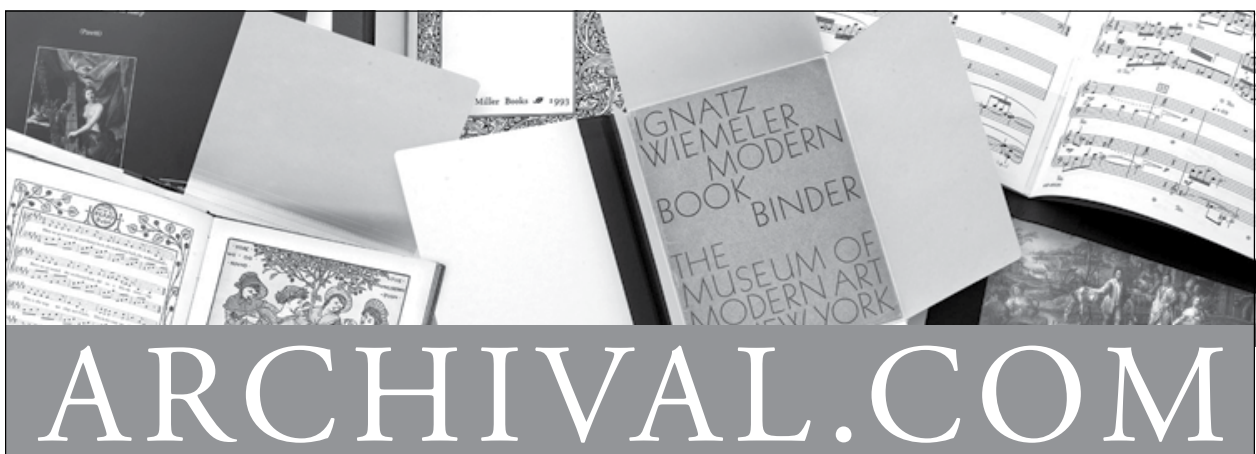

INNOVATIVE SOLUTIONS FOR PRESERVATION

Call for a complete catalog

Pamphlet Binders Music Binders

Archival Folders

Manuscript Folders

Hinge Board Covers

Academy Folders

Newspaper/Map Folders

Bound Four Flap

Enclosures

Archival Binders
Polypropylene Sheet \& Photo Protectors Archival Boards

Adhesives

Bookkeeper

Century Boxes

Conservation Cloths

Non-Glare Polypropylene Book Covers

CoLibri Book Cover System
ARCHIVAL PRODUCTS

P.O. Box 1413

Des Moines, Iowa 50306-1413

Phone: 800.526.5640

Fax: 888.220.2397

E-mail: custserv@archival.com Web: archival.com 